\title{
Editorial: Advanced learning technologies
}

\section{Stephen J.H. Yang*}

Department of Computer Science and Information Engineering

National Central University, Taiwan

E-mail: jhyang@csie.ncu.edu.tw

\section{Gang-Shan Fu}

Department of Educational Science Shaanxi Normal University, China

E-mail: fugsh@snnu.edu.cn

\section{Yu-Ju Lan}

Department of Applied Chinese Language and Literature National Taiwan Normal University, Taiwan

E-mail: yujulan@gmail.com

\section{Jeff J.S. Huang}

Department of Computer Science and Information Engineering Hwa Hsia Institute of Technology, Taiwan

E-mail: Jeff@cc.hwh.edu.tw

*Corresponding author

\begin{abstract}
Recent rapid development of advanced information technology brings high expectations of its potential to improvement and innovations in learning. This special issue is devoted to using some of the emerging technologies issues related to the topic of education and knowledge sharing, involving several cutting edge research outcomes from recent advancement of learning technologies. Advanced learning technologies are the composition of various related technologies and concepts such as mobile technologies and social media towards learner centered learning. This editorial note provides an overview of relevant issues discussed in this special issue.
\end{abstract}

Keywords: Mobile technology; Social media; Learner-centered; Content adaption

Biographical notes: Dr. Stephen J.H. Yang is a Distinguished Professor of Computer Science \& Information Engineering, and the Associate Dean of Academic Affairs at the National Central University, Taiwan. Dr. Yang received his Ph.D. degree in Electrical Engineering \& Computer Science from the University of Illinois at Chicago in 1995. Dr. Yang has published over 180 papers, his research interests include knowledge management, Second Life, mobile learning, Web 2.0, semantic Web, social networks, context aware \& ubiquitous learning. 
Prof. Gang-Shan Fu is a Professor of Department of Educational Science at Shaanxi Normal University. He currently serves as a director of Shaanxi Normal primary and secondary education information technology institute. His research interests include network and e-learning in education, technology enhanced learning, educational theory and practice of information technology, intellect technology in education.

Dr. Yu-Ju Lan is currently an Associate Professor of Department of Applied Chinese Languages and Literature at National Taiwan Normal University. She received the B.S. degree in Computer Science from Chinese Culture University, Taipei, Taiwan, R.O.C., in 1990 and M.S. and Ph.D. degrees in Information and Computer Education from National Taiwan Normal University, Taiwan, in 1995 and 2006, respectively. Now she serves as an active reviewer of the Journal of Educational Technology \& Society. Her research interests include technology enhanced foreign language learning (TEFLL), online synchronous teacher training, language learning in virtual worlds, and mobile learning (ML).

Dr. Jeff J.S. Huang received his $\mathrm{PhD}$ degree in Computer Science and Information Engineering from the National Central University at Taiwan in 2010. He is now an Assistant Professor of the Department of Computer Science and Information Engineering, Hwa Hsia Institute of technology, Taiwan. His research interests include e-Portfolio, e-learning, Web 2.0, CSCW, and CSCL.

\section{Introduction}

This special issue is dedicated to papers selected from the Asia Pacific Conference on Technology Enhanced Learning (APTEL2011) and the Workshop on Real Education in Second Life in the 18th International Conference on Computers in Education (ICCE2011). The APTEL provides a forum for researchers in technology enhanced learning to share their findings and exchange their experiences in related studies and projects. The main theme of 2011 was Technology Enhanced Language Learning. Advanced learning technologies are the composition of various related technologies and concepts such as mobile technologies and social media enhanced students' learning towards learner centered learning. This editorial note provides an overview of relevant issues discussed in this special issue.

\section{Mobile technologies and social media enhanced learning}

Mobile technologies and social media have offered innovative and creative learning opportunities for education, such as blog-based learning, podcasting, Web content adaptation and social networking technologies. Furthermore, current research on technology enhanced learning has shifted their focus from technology to supporting factual and ubiquitous learning and the reinforcement of learning strategy to stimulate meaningful learning. The support of mobile and social technologies would help students to develop personalized learning strategy in their learning activities, such as self-paced learning, critical thinking and problem-solving.

Social media has become a major technology that supports content publishing and sharing over the Internet, such as Blog, Facebook, and Wiki. Social media refers to an expected second generation of Web technology that allows people to create, publish, 
exchange, share, and cooperate on information or knowledge in a new way of communication and collaboration. Therefore, the success of social media heavily relies on communication and collaboration among people over the Internet. However, there are some concerns such as how groups can be formed as communities of practice (CoP); and how $\mathrm{CoP}$ can be applied to the e-learning field to create social and collaborative learning space.

With mobile technologies, many content publishing tools have provided content adaptation facilities that transform Web pages into proper formats before delivering them to different receiving devices (Yang, Zhang, Tsai, \& Huang, 2010; Chen, Yang, \& Zhang, 2010; Yang, Zhang, \& Huang, 2008). This is because mobile devices have smaller screens, slower network connections, and less computing power. Therefore, it is very important to improve browsing functions on the mobile devices and make learners to enjoy mobile learning.

\section{Learner-centered e-learning}

Since the Web 2.0 information technology era, the instructional model has been gradually changed from the traditional model to the learner-centered model, where learners actively construct knowledge in their learning activities. As a result, personal life-long learning, self reflection and self-regulated learning capabilities have become increasingly important.

An electronic portfolio (e-Portfolio) is a digital electronic platform that has a strong relevance to learner-centered learning. An e-Portfolio stores visual and auditory content (including text, images, video, and sound) to demonstrate learners' competencies and reflections in a field of knowledge to a teacher, a colleague, a professional, or a community. The e-Portfolio is not only a learning tool to support a variety of pedagogical processes and assessment purposes, but also a private virtual space in a Web-based environment. The e-Portfolio learning process is consistent with the spirit of learnercentered learning, and being widely used in higher education. A number of recent studies have devoted their efforts to exploring the functions and learning benefits of e-Portfolio (Abrami \& Barrett, 2005; Lopez-Fernandez \& Rodriguez-Illera, 2009; Walz, 2006; Zellers \& Mudrey, 2007).

\section{Preview of papers}

Ten papers were included in this special issue. The first paper by Ellis S.J. Fu, Stephen J.H. Yang, and Jeff J.S. Huang observed and analyzed the students' blogging profiles, for learning assessment in the advanced learning technology area. It investigated the characteristics of blogging profiles of student bloggers in Taiwan using a content analysis on a popular blog Website. It was found that there were both significant gender and educational level differences in knowledge sharing among the participants, while blogroll links, posting categories, and blogging purposes also showed some interesting findings. These results provided some insights of students' blogging and provided implications to educators or sociologists.

In the second paper, Jeff J.S. Huang, Stephen J.H. Yang, Poky Y.F. Chiang, and Luis S.Y. Tzeng investigated the relationships between goal orientations, metacognitive strategies, and enjoyment when students use e-Portfolio. This paper was focused on goal 
orientation, metacognitive strategies and enjoyment to explain student learning behavior when using e-Portfolio. The results showed that students' mastery goals of using ePortfolio have a positive effect on their metacognitive strategies and enjoyment; that performance-approach goals have a negative effect on metacognitive strategies and a positive effect on enjoyment; that performance-avoidance goals have a positive effect on metacognitive strategies; that students' enjoyment has a positive effect on their metacognitive strategies; and that mastery goals can predict metacognitive strategies through enjoyment.

In the third paper, Mitsumasa Zushi, Yoshinori Miyazaki, and Ken Norizuki proposed a trace-based Web application mechanism to record students' study logs including their mouse trajectories, and to devise an IR tool that can summarize such diversified data. The results of an experiment were scrutinized to provide an analysis of the relationship between learners' activities and their study logs.

In the fourth paper, Joni Tzuchen Tang, Yu-Ju Lan, and Kuo-En Chang proposed Chinese learning community mechanism to enhance the oral communication skills of Chinese learners and to change their Chinese speaking and teaching behavior. The results showed that a virtual community can enhance learners' Chinese competence, and their instructional and leading skills can be developed in a virtual community situation.

In the fifth paper, Li-Chun Wang and Ming-Puu Chen investigated the effects of novices' learning style and gender consciousness on learning of programming concepts from game-based learning activities. The results revealed that (1) for the programming comprehension performance, the convergers outperformed the divergers, (2) participants' learning style and gender consciousness significantly affected their project performance, (3) for the high gender consciousness learners, the convergers performed better at abstract conceptualization and active experimentation than the divergers did, (4) for the divergers, the low gender consciousness learners possessed lower stereotype and were willing to challenge and performed better than the high gender consciousness learners, and (5) all the participants revealed positive intrinsic and extrinsic motivation.

In the sixth paper, Yih-Ruey Juang, Chih-Yueh Chou, and James Chan applied the self-explanation theory and reading comprehension strategies to design a lesson warm-up mechanism that scaffolds knowledge building. The authors implemented the idea into a blog-based learning system (BBLS). The result of teaching experiments revealed its positive effects on learning achievement, recall of old knowledge, connection between old and new knowledge, and understanding of new knowledge.

The seventh paper discussed the virtual community practice for educators in the Second Life. In this paper, Kim Holmberg reported the birth and growth of the EduFinland community in the virtual world of Second Life and discussed lessons learned during the years of its existence. They described examples of how virtual worlds can in some cases bring added value to education. Besides, the authors discussed implications for the future development and evolution of virtual worlds in education and educational communities.

In the eighth paper, Robert Chartrand discussed the potential of the Internet in language learning in terms of vast resources of authentic written, audio, and video materials to supplement lessons. With the Internet and other Web-based technologies, educators can find a wide assortment of materials for learners to study in class or after class so as to encourage learners' independence and autonomy. It was found that language learners with new technologies produced more meaningful output, where motivational, pedagogical, and affective factors were persuasive arguments for making an 
effort to experiment with the technology, and teachers could contributed significantly to learners' progress.

The ninth paper by Jeff J.S. Huang, Stephen J.H. Yang, Zac S.C. Chen, and Frank C.C. Wu proposed a fuzzy-based approach to developing adaptable content to view and read easily on mobile devices. The content adaption technology was presented to improve mobile Internet navigation and make learners to enjoy the mobile learning.

In the last paper, Jing Zhao and Jianli Jiao discussed the use of podcasting for training of pre-service teachers. The authors designed a prototype of TSTOP (Teaching Skills Training on Podcasting) for developing pre-service teachers' professional skills in classrooms. It was found that podcasting effectively enhanced pre-service teachers' training in classrooms and improved their interests and motivations, since it not only uses videos and audios to train teaching skills, but also helps learners to analyze and assess their training process and results. 


\section{References}

Abrami, P. C., \& Barrett, H. (2005). Directions for research and development on electronic portfolios. Canadian Journal of Learning and Technology, 31(3), 1-6.

Chen, R. C. S., Yang, S. J. H., \& Zhang, J. (2010). Enhancing the precision of content analysis in content adaptation using entropy-based fuzzy reasoning. Expert Systems with Applications, 37(8), 5706-5719.

Lopez-Fernandez, O., \& Rodriguez-Illera, J. L. (2009). Investigating university students' adaptation to a digital learner course portfolio. Computers \& Education, 52(2), 608616.

Walz, P. (2006). An overview of student e-portfolio functions. In A. Jafari \& C. Kaufman (Eds.), Handbook of Research on ePortfolio (chap. 19, pp. 194-204). London: Idea Group Reference.

Yang, S. J. H., Zhang, J., \& Huang, A. F. M. (2008). Applying web page adaptation technique to the augmentation of mobile learning. Journal of Research and Practice in Technology Enhanced Learning, 3(3), 253-273.

Yang, S. J. H., Zhang, J., Tsai, S. T. C., \& Huang, J. J. S. (2010). Applying semantic segment detection to web page presentation on the mobile Internet. Journal of Information Science and Engineering. 1(1), 96-129.

Zellers, M., \& Mudrey, R. (2007). Electronic portfolios and metacognition: A phenomenological examination of the implementation of e-portfolio from the Instructors' perspective. International Journal of Instructional Media, 34(4), 419-430. 